Manar Y Abdul-Qadir BDS, MSc (Asst. Lec.)

\section{Dental Arch and Mesiodistal Crown Dimensions in Normal, Crowded, and Spaced Samples}

\author{
Dept of Pedod, Orthod and Prev Dentistry \\ College of Dentistry, University of Mosul
}

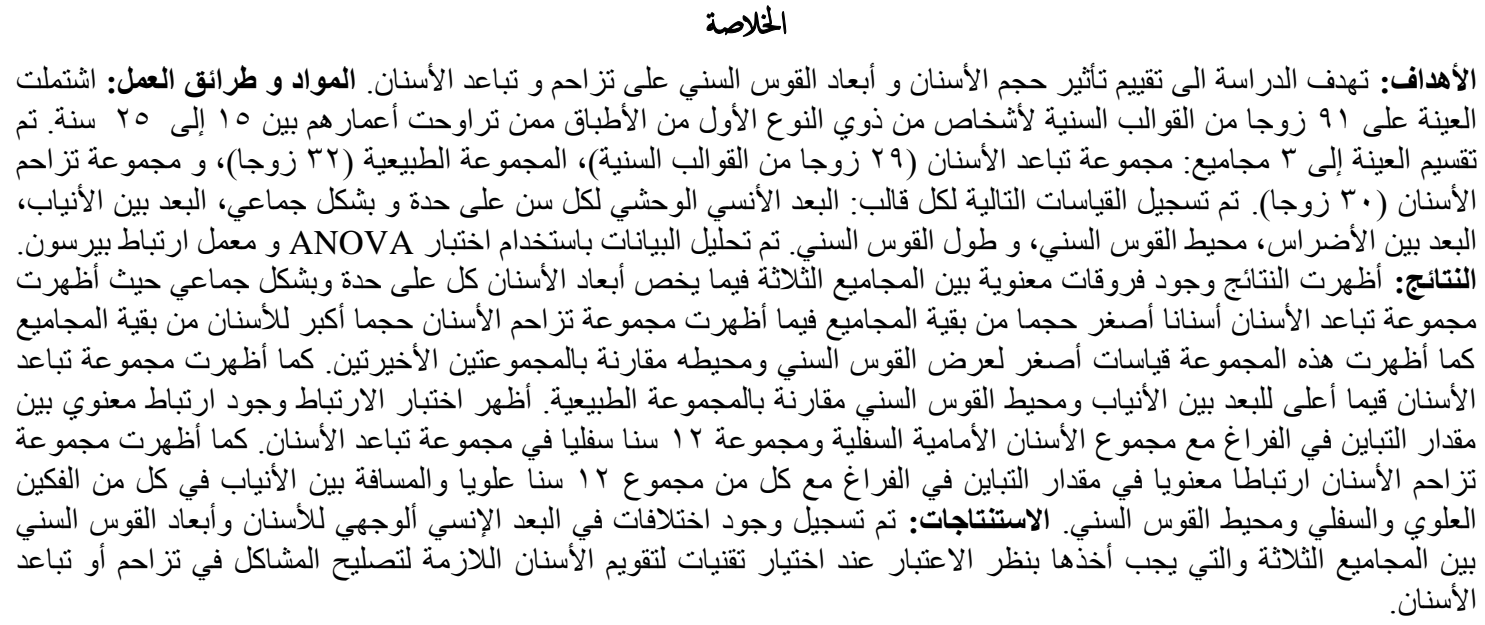

ABSTRACT

Aims: To investigate the contribution of both tooth size and dental arch dimensions to dental crowding and spacing. Materials and Methods: ninty one pairs of dental casts of subjects aged 15-25 years with $\mathrm{Cl}$ I molar occlusion were selected for this study. The sample was divided into 3 groups: the spaced (29 pairs), the normal (32 pairs), and the crowded (30 pairs) groups. For each pair of dental casts the following parameters were measured: individual and combined mesiodistal tooth dimensions, intercanine and intermolar widths, arch perimeter, and arch length. One way analysis of variance and Pearson correlation coefficient were used for the statistical analysis. Results: significant difference was noticed among the three groups for tooth dimension both individually and combined. The spaced group showed the smallest tooth size, while the crowded group was found to have the largest tooth size among the three groups. The crowded group showed a significantly smaller upper and lower arch widths and arch perimeter when compared with the spaced and normal groups. The spaced group showed larger upper and lower intercanine widths and upper arch perimeter when compared with the normal group, but this difference was significant only for upper intercanine width. Correlation analysis revealed that spaced group has significant correlation between the space discrepancy and the sums of 6 anterior and 12 teeth in the lower arch. While, space discrepancy in the crowded group showed significant correlation with the sum of 12 upper teeth and upper intercanine width and with lower intercanine width and arch perimeter. Conclusions: variations in mesiodistal tooth size and dental arch dimensions do exist among crowded, spaced, and normal dental arches. These variations should be taken into consideration when choosing orthodontic treatment techniques used for resolving problems related to space discrepancy.

Keywords: Mesiodistal tooth dimension, Dental arch dimension, Spacing, Crowding.

Abdul-Qadir MY. Dental Arch and Mesiodistal Crown Dimensions in Normal, Crowded, and Spaced Samples. Al-Rafidain Dent J. 2011; 11(2):211-218.

Received: 25/11/2008 Sent to Referees: 30/11/2008

Accepted for Publication: 21/1/2009

\section{INTRODUCTION}

Dental crowding and spacing are common traits of malocclusion which have special implications in orthodontic treatment planning as well as in stability and relapse after treatment. ${ }^{(1)}$ Crowding and 
spacing can be described as an expression of an altered ratio between tooth size and dental arch dimensions, both of which are influenced by hereditary and environmental factors. ${ }^{(2-4)}$

The orthodontic literature has an ample amount of information regarding the contribution of tooth size and arch dimensions to crowding. ${ }^{(5-12)}$ Some authors stated that crowded arches have larger mesiodistal tooth dimensions than non crowded arches. ${ }^{(5-9)}$ However others reported that dental arch size has the greater contribution to development of dental crowding. ${ }^{(10-}$ 12)

On the other hand, few studies have explored the relation of tooth size and dental arch dimensions to spacing. ${ }^{(13-15)}$ In their study, Steigmen et al., ${ }^{(13)}$ revealed that in females the mean mesiodistal widths were significantly narrower in spaced dentitions, while spaced maxillary arches in males had significantly greater intercuspid and interbicuspid widths; they concluded that this indicates two different causes of the spaced dentitions. Bernabi et $a l .{ }^{(14)}$ disclosed that the anterior and overall tooth width ratios and the differences between upper and lower tooth width sums are greater in subjects with crowding than in those with spaced arches. Puri et al., ${ }^{(15)}$ reported that mesiodistal crown dimension of teeth, both individually and combined, were significantly greater in crowded arches than in spaced dentitions.

It is important to clarify the role played by both tooth size and dental arch dimensions in the development of crowding and spacing, such an attempt will have a significant implication in the treatment techniques used for alleviation of these problems. Therefore, this study was designed to: (1) Compare, combined and individually, the mesiodistal tooth size among normal, crowded and spaced dentitions. (2) Compare dental arch dimensions among the three groups. (3) Determine the correlation of the degree of space discrepancy in relation to mesiodistal tooth widths and arch dimensions.

\section{MATERIALS AND METHODS}

Ninety one pairs of dental casts of subjects aged 15-25 years were used in this study, individuals within this age group have a relative stability of dental arch with very small and clinically undetectable changes in alignment and dimensions. ${ }^{(16,17)}$ The crowded and spaced samples were selected from dental casts available at Department of Pedodontics, Orthodontics and Preventive Dentistry and from the records of private practice of four orthodontists. All the dental casts of normal occlusion group were selected from University of Mosul dental students.

Each selected cast met the following criteria:

1. Full complement of permanent dentition excluding third molars ${ }^{(10)}$ with Class I molar relationship ${ }^{(9)}$.

2. Absence of anomalies in tooth number, size, or shape ${ }^{(14)}$ and absence of transverse discrepancy ${ }^{(18)}$.

3. No previous orthodontic treatment.

4. For better standardization additional criterion was considered which is absence of anterior dento-alveolar protrusion/ retrusion (as such conditions can affect dental arch dimensions).

Each selected dental cast was classified as crowded when there is more than $3 \mathrm{~mm}$ discrepancy, as spaced when there is more than $+3 \mathrm{~mm}$ discrepancy ${ }^{(15)}$, and as normal when there is $0 \pm 1.5 \mathrm{~mm}$ discrepancy. The crowded group included 30 pairs of casts (11 males and 19 females) with a discrepancy ranged from -3.15 to $10.8 \mathrm{~mm}$; the spaced group comprised 29 pairs of casts (10 males and 19 females) with a discrepancy ranged from 3.2 to $9.6 \mathrm{~mm}$, while 32 pairs of casts ( 18 males and 14 females) were included in the normal group.

The sample was not assorted into males and females groups because it was difficult to obtain equal numbers for each gender, and thus each dentition group was studied as a combined males and females sample.

With the use of electronic digital caliper (IOS, USA) the following measurements were made to the nearest $0.01 \mathrm{~mm}$ :

1. Mesiodistal crown widths of all teeth from the right to the left first permanent molar, then the sum of 6 anterior teeth and the sum of the 12 teeth were computed for each cast.

2. Intercanine width.

3. Intermolar width at mesiobuccal cusp tips.

4. Arch length: this was measured as the 
perpendicular distance from interincisal point to the line tangent to the distal surfaces of first permanent molars. ${ }^{(5)}$

5. Arch perimeter: this was measured using segmental technique in which the arch is measured in 6 segments. ${ }^{(5)}$

The data were analysed using SPSS program (version 11.5). Analysis of variance (ANOVA) and Duncan's Multiple Range Test were used to evaluate differences among the three groups. Pearson correlation coefficient was used to establish correlation of space discrepancy to combined mesiodistal tooth sums and arch dimensions.

\section{RESULTS}

The statistical analysis revealed a significant difference among the spaced, normal, and crowded groups regarding the sum of 6 anterior teeth and the sum of 12 teeth in the maxillary and mandibular arches. The crowded group showed the greatest mean values while the spaced group showed the lowest mean values (Table 1).

Mesiodistal crown dimensions of individual teeth were significantly different among the three groups. The spaced group demonstrated significantly smaller mesiodistal dimensions of all teeth when compared with both the normal and crowded groups.

The largest dimensions of individual teeth were presented by the crowded group, however this difference was significant for all teeth when compared with the spaced group; while when the crowded group was compared to the normal group the difference was significant in the right and left incisors and left canine in the upper arch and in all Mandibular teeth except the right canine and second premolar and left first and second premolars (Tables 2 and 3 ).

Table (1): Comparison of collective mesiodistal tooth dimensions among the three groups.

\begin{tabular}{|c|c|c|c|c|c|c|c|}
\hline Variable & Group & No. & Mean & SD & F value & $p$ value & $\begin{array}{c}\text { Duncan's } \\
\text { grouping }\end{array}$ \\
\hline \multirow{3}{*}{$\begin{array}{l}\text { Sum of } 6 \text { upper } \\
\text { anterior teeth }\end{array}$} & Spaced & 29 & 43.74 & 2.73 & \multirow{3}{*}{31.73} & \multirow{3}{*}{$.000 *$} & A \\
\hline & Normal & 32 & 46.57 & 2 & & & B \\
\hline & Crowded & 30 & 48.66 & 1.71 & & & $\mathrm{C}$ \\
\hline \multirow{3}{*}{$\begin{array}{l}\text { Sum of } 12 \text { up- } \\
\text { per teeth }\end{array}$} & Spaced & 29 & 89.59 & 4.89 & \multirow{3}{*}{25.00} & \multirow{3}{*}{$.000 *$} & $\mathrm{~A}$ \\
\hline & Normal & 32 & 94.54 & 3.83 & & & B \\
\hline & Crowded & 30 & 97.55 & 3.13 & & & $\mathrm{C}$ \\
\hline \multirow{3}{*}{$\begin{array}{l}\text { Sum of } 6 \text { lower } \\
\text { anterior teeth }\end{array}$} & Spaced & 29 & 34.15 & 2 & \multirow{3}{*}{35.01} & \multirow{3}{*}{$.000^{*}$} & $\mathrm{~A}$ \\
\hline & Normal & 32 & 36.63 & 1.96 & & & B \\
\hline & Crowded & 30 & 38.44 & 1.4 & & & $\mathrm{C}$ \\
\hline \multirow{3}{*}{$\begin{array}{l}\text { Sum of } 12 \text { low- } \\
\quad \text { er teeth }\end{array}$} & Spaced & 29 & 82.45 & 3.91 & \multirow{3}{*}{29.25} & \multirow{3}{*}{$.000^{*}$} & $\mathrm{~A}$ \\
\hline & Normal & 32 & 87.11 & 3.92 & & & $\mathrm{~B}$ \\
\hline & Crowded & 30 & 90.21 & 2.83 & & & $\mathrm{C}$ \\
\hline
\end{tabular}

* Groups with different letters are statistically different. * very highly significant at $p \leq .001$. 
Table (2): Mesiodistal dimensions of maxillary teeth in spaced, normal, and crowded groups.

\begin{tabular}{|c|c|c|c|c|c|c|c|}
\hline Variable & Group & No. & Mean & SD & F value & $p$ value & $\begin{array}{l}\text { Duncan's } \\
\text { grouping* }\end{array}$ \\
\hline \multirow{3}{*}{$\begin{array}{c}\mathbf{R} \text { central } \\
\text { incisor }\end{array}$} & Spaced & 29 & 8.27 & 0.56 & \multirow{3}{*}{21.88} & \multirow{3}{*}{$.000 * *$} & A \\
\hline & Normal & 32 & 8.69 & 0.49 & & & B \\
\hline & Crowded & 30 & 9.21 & 0.44 & & & $\mathrm{C}$ \\
\hline \multirow{3}{*}{$\begin{array}{l}\text { R lateral } \\
\text { incisor }\end{array}$} & Spaced & 29 & 6.21 & 0.50 & \multirow{3}{*}{24.12} & \multirow{3}{*}{$.000 * *$} & A \\
\hline & Normal & 32 & 6.78 & 0.47 & & & B \\
\hline & Crowded & 30 & 7.10 & 0.38 & & & $\mathrm{C}$ \\
\hline \multirow{3}{*}{$R$ canine } & Spaced & 29 & 7.36 & 0.45 & \multirow{3}{*}{20.00} & \multirow{3}{*}{$.000 * *$} & $\mathrm{~A}$ \\
\hline & Normal & 32 & 7.88 & 0.39 & & & B \\
\hline & Crowded & 30 & 8.06 & 0.36 & & & $\mathrm{~B}$ \\
\hline \multirow{3}{*}{$\begin{array}{l}\text { R 1st pre- } \\
\text { molar }\end{array}$} & Spaced & 29 & 6.69 & 0.43 & \multirow{3}{*}{9.16} & \multirow{3}{*}{$.000 * *$} & $\mathrm{~A}$ \\
\hline & Normal & 32 & 7.06 & 0.47 & & & $\mathrm{~B}$ \\
\hline & Crowded & 30 & 7.18 & 0.35 & & & $\mathrm{~B}$ \\
\hline \multirow{3}{*}{$\begin{array}{c}\text { R 2nd } \\
\text { premolar }\end{array}$} & Spaced & 29 & 6.43 & 0.47 & \multirow{3}{*}{8.68} & \multirow{3}{*}{$.000 * *$} & $\mathrm{~A}$ \\
\hline & Normal & 32 & 6.78 & 0.37 & & & B \\
\hline & Crowded & 30 & 6.93 & 0.40 & & & $\mathrm{~B}$ \\
\hline \multirow{3}{*}{$\begin{array}{l}\text { R first mo- } \\
\quad \text { lar }\end{array}$} & Spaced & 29 & 9.81 & 0.54 & \multirow{3}{*}{7.60} & \multirow{3}{*}{$.001 *$} & A \\
\hline & Normal & 32 & 10.14 & 0.47 & & & $\mathrm{~B}$ \\
\hline & Crowded & 30 & 10.31 & 0.34 & & & $\mathrm{~B}$ \\
\hline \multirow{3}{*}{$\begin{array}{l}\text { L central } \\
\text { incisor }\end{array}$} & Spaced & 29 & 8.30 & 0.52 & \multirow{3}{*}{17.72} & \multirow{3}{*}{$.000 * *$} & $\mathrm{~A}$ \\
\hline & Normal & 32 & 8.67 & 0.46 & & & B \\
\hline & Crowded & 30 & 9.12 & 0.45 & & & $\mathrm{C}$ \\
\hline \multirow{3}{*}{$\begin{array}{c}\text { L lateral } \\
\text { incisor }\end{array}$} & Spaced & 29 & 6.24 & 0.53 & \multirow{3}{*}{16.93} & \multirow{3}{*}{$.000 * *$} & A \\
\hline & Normal & 32 & 6.69 & 0.39 & & & B \\
\hline & Crowded & 30 & 7.01 & 0.48 & & & $\mathrm{C}$ \\
\hline \multirow{3}{*}{ L canine } & Spaced & 29 & 7.33 & 0.42 & \multirow{3}{*}{24.46} & \multirow{3}{*}{$.000 * *$} & $\mathrm{~A}$ \\
\hline & Normal & 32 & 7.84 & 0.39 & & & B \\
\hline & Crowded & 30 & 8.12 & 0.39 & & & $\mathrm{C}$ \\
\hline & Spaced & 29 & 6.69 & 0.41 & & & $\mathrm{~A}$ \\
\hline L 1st pre- & Normal & 32 & 7.05 & 0.43 & 10.85 & $.000^{* *}$ & B \\
\hline & Crowded & 30 & 7.22 & 0.37 & & & $\mathrm{~B}$ \\
\hline & Spaced & 29 & 6.39 & 0.43 & & & $\mathrm{~A}$ \\
\hline L 2nd & Normal & 32 & 6.72 & 0.38 & 10.65 & $.000^{* *}$ & B \\
\hline premolar & Crowded & 30 & 6.93 & 0.44 & & & B \\
\hline & Spaced & 29 & 9.79 & 0.55 & & & $\mathrm{~A}$ \\
\hline L first mo- & Normal & 32 & 10.19 & 0.47 & 7.96 & $.001 *$ & B \\
\hline & Crowded & 30 & 10.30 & 0.38 & & & B \\
\hline
\end{tabular}


Table (3): Mesiodistal dimensions of mandibular teeth in spaced, normal, and crowded groups.

\begin{tabular}{|c|c|c|c|c|c|c|c|}
\hline Variable & Group & No. & Mean & SD & F value & $p$ value & $\begin{array}{c}\text { Duncan's } \\
\text { grouping } *\end{array}$ \\
\hline \multirow{3}{*}{$\begin{array}{l}\mathbf{R} \text { central } \\
\text { incisor }\end{array}$} & Spaced & 29 & 5.12 & 0.37 & \multirow{3}{*}{25.91} & \multirow{3}{*}{$.000 *$} & $\mathrm{~A}$ \\
\hline & Normal & 32 & 5.43 & 0.35 & & & B \\
\hline & Crowded & 30 & 5.80 & 0.26 & & & $\mathrm{C}$ \\
\hline \multirow{3}{*}{$\begin{array}{l}\mathbf{R} \text { lateral } \\
\text { incisor }\end{array}$} & Spaced & 29 & 5.60 & 0.37 & \multirow{3}{*}{27.08} & \multirow{3}{*}{$.000^{*}$} & $\mathrm{~A}$ \\
\hline & Normal & 32 & 5.96 & 0.39 & & & B \\
\hline & Crowded & 30 & 6.35 & 0.28 & & & $\mathrm{C}$ \\
\hline \multirow{3}{*}{$\mathbf{R}$ canine } & Spaced & 29 & 6.33 & 0.40 & \multirow{3}{*}{30.10} & \multirow{3}{*}{$.000^{*}$} & $\mathrm{~A}$ \\
\hline & Normal & 32 & 6.90 & 0.33 & & & $\mathrm{~B}$ \\
\hline & Crowded & 30 & 7.05 & 0.30 & & & B \\
\hline \multirow{3}{*}{$\begin{array}{c}\text { R 1st } \\
\text { premolar }\end{array}$} & Spaced & 29 & 6.65 & 0.28 & \multirow{3}{*}{16.40} & \multirow{3}{*}{$.000^{*}$} & $\mathrm{~A}$ \\
\hline & Normal & 32 & 7.03 & 0.42 & & & $\mathrm{~B}$ \\
\hline & Crowded & 30 & 7.25 & 0.37 & & & $\mathrm{C}$ \\
\hline \multirow{3}{*}{$\begin{array}{c}\text { R 2nd } \\
\text { premolar }\end{array}$} & Spaced & 29 & 6.77 & 0.28 & \multirow{3}{*}{11.29} & \multirow{3}{*}{$.000 *$} & $\mathrm{~A}$ \\
\hline & Normal & 32 & 7.12 & 0.38 & & & B \\
\hline & Crowded & 30 & 7.27 & 0.43 & & & $\mathrm{~B}$ \\
\hline \multirow{3}{*}{$\begin{array}{l}\text { R first } \\
\text { molar }\end{array}$} & Spaced & 29 & 10.62 & 0.58 & \multirow{3}{*}{11.02} & \multirow{3}{*}{$.000 *$} & $\mathrm{~A}$ \\
\hline & Normal & 32 & 11.02 & 0.55 & & & B \\
\hline & Crowded & 30 & 11.33 & 0.43 & & & $\mathrm{C}$ \\
\hline \multirow{3}{*}{$\begin{array}{l}\text { L central } \\
\text { incisor }\end{array}$} & Spaced & 29 & 5.15 & 0.36 & \multirow{3}{*}{18.50} & \multirow{3}{*}{$.000 *$} & $\mathrm{~A}$ \\
\hline & Normal & 32 & 5.44 & 0.44 & & & B \\
\hline & Crowded & 30 & 5.80 & 0.29 & & & $\mathrm{C}$ \\
\hline \multirow{3}{*}{$\begin{array}{l}\text { L lateral } \\
\text { incisor }\end{array}$} & Spaced & 29 & 5.59 & 0.35 & \multirow{3}{*}{25.85} & \multirow{3}{*}{$.000 *$} & A \\
\hline & Normal & 32 & 5.99 & 0.40 & & & $\mathrm{~B}$ \\
\hline & Crowded & 30 & 6.32 & 0.30 & & & $\mathrm{C}$ \\
\hline \multirow{3}{*}{$L$ canine } & Spaced & 29 & 6.34 & 0.37 & \multirow{3}{*}{31.18} & \multirow{3}{*}{$.000 *$} & $\mathrm{~A}$ \\
\hline & Normal & 32 & 6.89 & 0.37 & & & B \\
\hline & Crowded & 30 & 7.10 & 0.28 & & & $\mathrm{C}$ \\
\hline & Spaced & 29 & 6.70 & 0.32 & & & $\mathrm{~A}$ \\
\hline L 1st & Normal & 32 & 7.10 & 0.41 & 13.83 & $.000 *$ & $\mathrm{~B}$ \\
\hline premolar & Crowded & 30 & 7.25 & 0.36 & & & B \\
\hline & Spaced & 29 & 6.82 & 0.32 & & & $\mathrm{~A}$ \\
\hline L 2nd & Normal & 32 & 7.15 & 0.33 & 10.40 & $.000^{*}$ & $\mathrm{~B}$ \\
\hline premolar & Crowded & 30 & 7.28 & 0.41 & & & $\mathrm{~B}$ \\
\hline & Spaced & 29 & 10.70 & 0.67 & & & $\mathrm{~A}$ \\
\hline L first & Normal & 32 & 11.02 & 0.54 & 9.63 & $.000^{*}$ & $\mathrm{~B}$ \\
\hline & Crowded & 30 & 11.37 & 0.38 & & & $\mathrm{C}$ \\
\hline
\end{tabular}

$\mathrm{R}=$ right, $\mathrm{L}=$ left. $*$ Groups with different letters are statistically different. *very highly significant at $p \leq .001$.

Significant difference was noticed among the 3 groups in all upper and lower arch dimensions except for upper and lower arch lengths. The intercanine and intermolar widths and arch perimeter for both arches were significantly narrower in the crowded group compared with the normal and spaced groups; on the other hand all arch dimensions showed a non significant difference between the spaced and normal groups except the upper intercanine width which was significantly wider in the spaced group as demonstrated in Table (4).

The correlation coefficients for the combined mesiodistal tooth widths of 6 and 12 teeth and arch dimensions in relation to the amount of space discrepancy are demonstrated in Table (5). In the spaced group, the degree of space discrepancy was found to have significant correlation only with the sums of lower six anterior and 12 teeth. While, the space 
discrepancy in the crowded group showed significant correlation with the sum of up- per 12 teeth, upper and lower intercanine widths, and lower arch perimeter.

Table (4): Comparison of dental arch dimensions among the three groups.

\begin{tabular}{|c|c|c|c|c|c|c|c|}
\hline Variable & Group & No. & Mean & SD & F value & $p$ value & $\begin{array}{c}\text { Duncan's } \\
\text { grouping* }\end{array}$ \\
\hline \multirow{3}{*}{ Upper ICW } & Spaced & 29 & 35.44 & 1.91 & \multirow{3}{*}{21.25} & \multirow{3}{*}{$.000 * * *$} & $\mathrm{~A}$ \\
\hline & Normal & 32 & 34.45 & 1.39 & & & $\mathrm{~B}$ \\
\hline & Crowded & 30 & 32.58 & 1.28 & & & $\mathrm{C}$ \\
\hline \multirow{3}{*}{ Upper IMW } & Spaced & 29 & 52.12 & 2.56 & \multirow{3}{*}{4.46} & \multirow{3}{*}{$.015^{*}$} & $\bar{A}$ \\
\hline & Normal & 32 & 52.13 & 1.95 & & & A \\
\hline & Crowded & 30 & 50.42 & 2.46 & & & B \\
\hline \multirow{3}{*}{$\begin{array}{l}\text { Upper arch } \\
\text { perimeter }\end{array}$} & Spaced & 29 & 95.53 & 4.96 & \multirow{3}{*}{4.57} & \multirow{3}{*}{$.013^{*}$} & $\mathrm{~A}$ \\
\hline & Normal & 32 & 94.84 & 3.68 & & & A \\
\hline & Crowded & 30 & 92.35 & 2.58 & & & B \\
\hline \multirow{3}{*}{$\begin{array}{l}\text { Upper arch } \\
\text { length }\end{array}$} & Spaced & 29 & 36.72 & 2.43 & \multirow{3}{*}{.302} & \multirow{3}{*}{.74} & $\mathrm{~A}$ \\
\hline & Normal & 32 & 37.04 & 1.74 & & & A \\
\hline & Crowded & 30 & 36.67 & 1.55 & & & A \\
\hline \multirow{3}{*}{ Lower ICW } & Spaced & 29 & 27.18 & 1.83 & \multirow{3}{*}{6.99} & \multirow{3}{*}{$.002 * *$} & $\mathrm{~A}$ \\
\hline & Normal & 32 & 26.45 & 1.71 & & & A \\
\hline & Crowded & 30 & 25.28 & 1.81 & & & $\mathrm{~B}$ \\
\hline \multirow{3}{*}{ Lower IMW } & Spaced & 29 & 44.78 & 2.64 & \multirow{3}{*}{12.77} & \multirow{3}{*}{$.000 * * *$} & $\mathrm{~A}$ \\
\hline & Normal & 32 & 44.86 & 1.57 & & & $\mathrm{~A}$ \\
\hline & Crowded & 30 & 42.18 & 2.37 & & & B \\
\hline \multirow{3}{*}{$\begin{array}{l}\text { Lower arch } \\
\text { perimeter }\end{array}$} & Spaced & 29 & 86.62 & 3.53 & \multirow{3}{*}{4.78} & \multirow{3}{*}{$.011^{*}$} & $\mathrm{~A}$ \\
\hline & Normal & 32 & 86.81 & 3.52 & & & A \\
\hline & Crowded & 30 & 84.23 & 3.09 & & & $\mathrm{~B}$ \\
\hline \multirow{3}{*}{$\begin{array}{l}\text { Lower arch } \\
\text { length }\end{array}$} & Spaced & 29 & 32.35 & 1.7 & \multirow{3}{*}{2.07} & \multirow{3}{*}{.132} & $\mathrm{~A}$ \\
\hline & Normal & 32 & 32.07 & 1.99 & & & A \\
\hline & Crowded & 30 & 31.3 & 1.91 & & & A \\
\hline
\end{tabular}

$\mathrm{ICW}=$ intercanine width, IMW $=$ intermolar width. $*$ Groups with different letters are statistically different. * significant at $p \leq .05, * *$ highly significant at $p \leq .01, * * *$ very highly significant at $p \leq .001$.

Table (5): Correlation of space discrepancy to combined mesiodistal tooth sums and arch dimensions.

\begin{tabular}{ccccccccc}
\hline Group & \multirow{2}{*}{ No. } & $\begin{array}{c}\text { Space dis- } \\
\text { crepancy }\end{array}$ & $\begin{array}{c}\text { Sum of 6 } \\
\text { anteriors }\end{array}$ & $\begin{array}{c}\text { Sum of 12 } \\
\text { teeth }\end{array}$ & ICW & IMW & $\begin{array}{c}\text { Arch pe- } \\
\text { rimeter }\end{array}$ & $\begin{array}{c}\text { Arch } \\
\text { length }\end{array}$ \\
\hline \multirow{2}{*}{ Spaced } & \multirow{2}{*}{29} & Upper & -0.24 & -0.20 & 0.09 & -0.14 & 0.14 & 0.20 \\
& Lower & $-0.52^{*}$ & $-0.51^{*}$ & 0.17 & -0.001 & -0.04 & 0.07 \\
\hline $\begin{array}{c}\text { Crowd- } \\
\text { ed }\end{array}$ & \multirow{2}{*}{30} & Upper & 0.39 & $0.57^{* *}$ & $-0.46^{*}$ & -0.09 & -0.13 & -0.001 \\
\hline
\end{tabular}

$\mathrm{ICW}=$ intercanine width, IMW $=$ intermolar width. ${ }^{*}$ Significant at $p \leq .05, * *$ highly significant at $p \leq .01$.

\section{DISCUSSION}

This study focused on investigating the contribution of tooth size and arch size to dental crowding and spacing. The sums of six anterior teeth and the twelve teeth in both arches were significantly greater in the crowded group compared with the normal group. This supports the findings of previous studies that explored the etiol- ogy of dental crowding. ${ }^{(9,15,19)}$ On the other hand, it does not support the findings of Howe et al., ${ }^{(10)}$ and Radnzic ${ }^{(12)}$, this conflict may be attributed to variation in sample selection. Howe et al., ${ }^{(10)}$ studied a sample of subjects ranged in their age from 9 to 44 years while the sample studied by Radnzic ${ }^{(12)}$ was selected at random without paying any attention to the type of 
dental occlusion. Significantly smaller sums of the six anterior and the 12 teeth in both arches were reported for the spaced group compared with both the crowded and normal groups. These findings agree with those of Puri et al. ${ }^{(15)}$ and with the results of Steigman et al., ${ }^{(13)}$ in females.

When tooth size was compared individually, significantly smaller mesiodistal dimensions of teeth was noticed in spaced group when compared with both normal and crowded groups. This comes in accordance with the results of Puri et al., ${ }^{(15)}$ except that when they compared spaced and normal groups significant difference was noticed only for right premolars in the upper arch and for right incisors and second premolars and left incisors and canine in the lower arch. Comparison between normal and crowded groups showed a significantly greater dimension in crowded group for upper and lower incisors which coincides with the findings of previous studies. ${ }^{(5,7,20)}$ The results of the present study support the findings of Yoshihara et al., ${ }^{(6)}$ and Frederick ${ }^{(21)}$ who investigated the relation between upper incisors and crowding and they also support the findings of Imai et al., ${ }^{(2)}$ whom their investigation was confined to lower incisors. However, the crowded and normal groups demonstrated a non significant difference in mesiodistal dimensions of upper and lower premolars and upper molars, thus an inference can be drawn that the difference in the sum of 12 teeth between the crowded and the normal groups is related mainly to upper and lower incisors teeth sizes.

The significantly smaller upper and lower arch widths and arch perimeter that were reported for the crowded group come in accordance with Al-Khatib ${ }^{(5)}$ except that in his study the difference in intercanine width was not significant. In their study, Poosti and $\mathrm{Jalali}^{(9)}$ reported a significantly narrower upper and lower intercanine widths and upper intermolar width in crowded arches with $\mathrm{Cl}$ I molar relations, while no significant difference was reported regarding arch perimeter in both arches which contradicts the results of the present study. This may be related to variation in the method used for measuring arch perimeter between the two studies. The find- ings of smaller upper and lower intermolar widths are also supported by those of Kuntz et al., ${ }^{(23)}$.

On the other hand, arch dimensions revealed no significant difference between the spaced and normal groups, except for upper intercanine width. This finding combined with the significant correlation noticed between the amount of space discrepancy and the sums of 6 and 12 lower teeth in spaced sample, may suggest a greater contribution of tooth size to dental spacing. In considering crowded sample, significant correlation was found between space discrepancy and the sum of 12 teeth and intercanine width in the upper arch and with intercanine width and arch perimeter in the lower arch. This along with the findings of larger teeth and smaller arch dimensions in the crowded group compared with the normal group can lead to the conclusion that $\mathrm{Cl}$ I crowded arches involve both larger mesiodistal tooth sizes and smaller than normal arch dimensions.

\section{CONCLUSIONS}

Mesiodistal tooth dimensions, both individually and combined, differ significantly among normal, spaced, and crowded dental arches. The crowded group was found to have the largest tooth size followed by the normal and the spaced groups. All dental arch dimensions, except arch length, were significantly smaller in the crowded group compared with normal and spaced groups. Spaced dental arches were found to have significant correlation between space discrepancy and tooth size, while crowded dental arches showed significant correlation between space discrepancy and both tooth size and arch dimensions (in particular intercanine width).

\section{REFERENCES}

1. Rhee SH, Nahm DS. Triangular shaped incisor crowns and crowding. Am J Orthod Dntofacial Orthop. 2000; 118(6): 624628.

2. Mossey PA. The heritability of malocclusion: Part 2. The influence of genetics in malocclusion. J Orthod.1999; 26(3): 195203.

3. Dempsey PJ, Townsend GC. Genetic and environmental contribution to variation in 
human tooth size. Heredity. 2001; 86(6): 685-693.

4. Gkantidis N, Psomiadis S, Topouzelis N. Teeth spacing: etiology and treatment. Hellenic Orthodontic Review. 2007; 10(2): 75-92.

5. Al-Khatib AR. Relationship of anterior dental crowding with mesiodistal crowns width of anterior teeth and dental arch dimensions in $\mathrm{Cl}$ I molar occlusion: A cross sectional study of pupils aged 12-15 years. MSc. Thesis. College of Dentistry. University of Mosul. 1997.

6. Yoshihara T, Matsumoto Y, Suzuki J, Sato $\mathrm{N}$, Oguchi H. Effect of serial extraction alone on crowding: Relationships between tooth width, arch length, and crowding. Am J Orthod Dntofacial Orthop. 1999; 116(6): 691-696.

7. Janosevic M, Filipovic G, Stankovic S, Janjic OT. Influence of the size of incisors on the occurrence of crowding. Facta Universitatis: Medicine and Biology. 2006; 13(1): 36-43.

8. Bernabe E, Flores-Mir C. Dental morphology and crowding: A multivariate approach. Angle Orthod. 2006; 76(1):20-25.

9. Poosti M, Jalali T. Tooth size and arch dimensions in uncrowded versus crowded Cl I malocclusions. J Contemp Dent Pract. 2007; 8(3): 45-52.

10. Howe RP, McNamara JA Jr, O'Connor KA. An examination of dental crowding and its relationship to tooth size and arch dimension. Am J Orthod. 1983; 83(3): 363-373.

11. Gilmore CA, Little RM. Mandibular incisor dimensions and crowding. Am J Orthod. 1984; 86(3): 493-502.

12. Radnzic D. Dental crowding and its relationship to mesiodistal crown diameters and arch dimensions. Am J Orthod Dntofacial Orthop. 1988; 94(1): 50-56.

13. Steigman S, Gershkovitz E, Harari D. Characteristics and stability of spaced dentition. Angle Orthod. 1985; 55(4): 321-
328.

14. Bernabe E, Villanueva KM, Flores-Mir C. Tooth width ratios in crowded and non crowded dentitions. Angle Orthod. 2004; 74(6): 765-768.

15. Puri N, Pradhan KL, Chandna A, Sehgal V, Gupta R. Biometric study of tooth size in normal, crowded and spaced permanent dentitions. Am J Orthod Dntofacial Orthop. 2007; 132(3): 279.e7-279.e14.

16. Richardson ME. Lower arch crowding in the young adult. Am J Orthod Dntofacial Orthop. 1992; 101( ):132-137.

17. Richardson ME, Gormley JS. Lower arch crowding in the third decade. Europ J Orthod. 1998; 20: 597-607.

18. AlKhateeb SN, Abu Alhaija ESJ. Tooth size discrepancies and arch parameters among different malocclusions in a Jordanian sample. Angle Orthod. 2006; 76(3): 459-465.

19. Doris JM, Bernard BW, Kuftinec MM, Stom D. A biometric study of tooth size and dental crowding. Am J Orthod. 1981; 79: 326-336.

20. Agenter MK. Influence of tooth crown size on malocclusion. MSc. Thesis. Health Science Center. University of Tennessee. 2008.

21. Frederick KK. Maxillary incisor crown form and crowding in adolescent orthodontic patients. MSc. Thesis. Health Science Center. University of Tennessee. 2008.

22. Imai H, Kuwana R, Yonezu T, Yakushiji $M$. The relation between tooth shape ratio and incisor arrangement in Japanese children. Bull Tokyo Dent Coll. 2006; 47(2): $45-50$.

23. Kuntz TR, Staley RN, Bigelow HF, Kremenak CR, Kohout FJ, Jakobsen JR. Arch widths in adults with Class I crowded and Class III malocclusions compared with normal occlusions. Angle Orthod. 2008; 78(4): 597-603. 